\title{
A CONSTITUIÇÃO DOS ACERVOS DO GRUPO DE PESQUISA HISTÓRIA DA ALFABETIZAÇÃO, LEITURA, ESCRITA E DOS LIVROS ESCOLARES E SUA CONTRIBUIÇÃO PARA AS INVESTIGAÇÕES EM EDUCAÇÃO' ${ }^{1}$ \\ DOI: http://dx.doi.org/10.1590/2236-3459/57961
}

\section{THE HISTORY OF LITERACY, READING, WRITING AND TEXTBOOKS RESEARCH GROUP ORGANIZED COLLECTION AND ITS CONTRIBUTION TO THE EDUCATION RESEARCH}

\author{
Eliane Teresinha Peres \\ Universidade Federal de Pelotas, Brasil. \\ Chris de Azevedo Ramil \\ Universidade Federal de Pelotas, Brasil.
}

$\cos 8$

\section{Introdução}

O grupo de pesquisa História da Alfabetização, Leitura, Escrita e dos Livros Escolares - Hisales -, cadastrado no CNPq desde 2006, é vinculado ao Programa de PósGraduação em Educação da Faculdade de Educação da Universidade Federal de Pelotas e reúne pesquisadores desta e de outras instituições de ensino da região Sul: Instituto Federal de Educação, Ciência e Tecnologia Sul-Rio-Grandense - IFSul, Fundação Universidade Federal do Rio Grande - Furg, Universidade Federal do Pampa - Unipampa. Sob a coordenação da professora dra. Eliane Peres, conta com a participação de pesquisadores e alunos de graduação e de pós-graduação.

\footnotetext{
${ }^{1}$ Este texto contou com a colaboração de Cícera Marcelina Vieira, Mônica Maciel Vahl e Francieli Daiane Borges. A elas agradecemos as contribuições. 
As pesquisas realizadas no Hisales se inserem em três eixos de estudos: investigações sobre a história alfabetização; pesquisas acerca das práticas escolares e não-escolares de leitura e escrita - cultura escrita e práticas de letramentos; análises da produção, circulação e utilização de livros escolares elaborados por autoras gaúchas, especialmente entre os anos de 1940-1980, período da influência do Centro de Pesquisas e Orientações Educacionais - CPOE $^{2}$.

Além da investigação na área de alfabetização, da leitura, da escrita e dos livros didáticos, o Hisales tem como um de seus objetivos fundamentais a constituição de acervos para manutenção da história e da memória da alfabetização e da escolarização primária, em especial do Rio Grande do Sul. O referido grupo possui importantes acervos: cartilhas e livros de alfabetização nacionais e estrangeiros do século 19 aos dias atuais; livros didáticos elaborados por autoras gaúchas entre os anos de 1940 e 1980; cadernos de alunos em fase de alfabetização do período de 1930 até a atualidade; cadernos de planejamento de professoras alfabetizadoras dos anos de 1960 aos dias atuais; materiais didático pedagógicos diversos: mobiliários, utensílios e materiais utilizados no ambiente escolar.

O conjunto dessas coleções têm contribuído como fonte e objeto nas investigações desenvolvidas, tanto por alunos de programas de pós-graduação, quanto por estudantes de iniciação científica, colaborando, desse modo, na problematização e análise de diferentes aspectos relacionados à História da Educação, especialmente do Rio Grande do Sul.

O presente artigo apresenta esses acervos, considerando sua constituição, organização e manutenção desde a criação do grupo em 2006.

\section{A constituição do acervo}

O grupo de pesquisa Hisales tem trabalhado na perspectiva da construção de acervos documentais que preservem a história e a memória da alfabetização, salvaguardando fontes que permitem uma melhor compreensão dos processos educacionais numa perspectiva histórica.

Os materiais que integram os acervos passam por tratamentos específicos que envolvem etapas como a limpeza, a catalogação e o armazenamento, com vistas ao cuidado com sua conservação e preservação. Novos itens são adquiridos por integrantes do grupo de pesquisa e recebidos por meio de doações das diferentes redes de ensino e da comunidade em geral. A divulgação do trabalho do grupo e a solicitação de doações de materiais, em qualquer estado de conservação, têm sido feita pela divulgação em eventos de educação, de cartazes, flyers impressos e via internet, nas redes sociais, no site do Hisales ${ }^{3}$ e, também, via e-mail.

Nos últimos anos o cenário acadêmico educacional experimenta a ampliação de estudos de cunho histórico, no qual é observado o crescente movimento de constituição

${ }^{2}$ O CPOE atuou no Estado do Rio Grande de Sul entre os anos de 1942 a 1970 e exerceu relevante papel no contexto educacional gaúcho ao intervir na organização do ensino, centralizar atividades e coordenar a execução de políticas públicas. Foi responsável pela consolidação de um projeto político-pedagógico em que os saberes que se afirmavam como novos e científicos, proveram as bases para a centralização das atividades e para a constituição de diferentes formas de controle e vigilância (Peres, 2000; Quadros, 2006).

${ }^{3}$ Ver http://wp.ufpel.edu.br/hisales. A sala do grupo de pesquisa Hisales está situada no Campus Lobo da Costa da UFPel, localizado na Rua Lobo da Costa, 1877, Térreo, Pelotas/RS.

\begin{tabular}{|l|l|l|l|l|r|}
\hline Hist. Educ. [Online] & Porto Alegre & v. 19 & n. 47 & Set./dez., 2015 & p. 297-311
\end{tabular}


de acervos por parte de pesquisadores que procuram preservar e analisar a história da educação brasileira sobre diferentes aspectos. Para Kirchner (2008), o potencial histórico dos acervos colabora para a renovação das práticas de pesquisas e originam novas abordagens metodológicas. Temos apostado nisso ao constituir os acervos do Hisales.

De acordo com Camargo (1999), tem sido uma tendência brasileira que grupos vinculados às universidades assumam parte da responsabilidade na manutenção de conjuntos documentais a partir do estabelecimento de centros de guarda de fontes históricas, em uma política voltada para a preservação do patrimônio. No campo da História da Educação essa tendência é percebida em projetos como, por exemplo, o Banco de Dados de Livros Escolares Brasileiros - Livres/USP -, coordenado por Circe Bittencourt. Entre as principais vantagens do envolvimento das universidades neste tipo de ação está a conservação de fontes, a reunião de informação especializada, a democratização ao acesso de materiais de pesquisa, o estímulo a novos pesquisadores (Camargo, 1999).

A seguir são apresentados alguns dados sobre os acervos do grupo de investigação Hisales, que mostram as quantidades existentes em cada coleção e algumas de suas principais características.

\section{Cartilhas e livros de alfabetização nacionais e estrangeiros}

Em relação às cartilhas e aos livros de alfabetização ${ }^{4}$ há, nesse momento no acervo, 909 exemplares nacionais e 126 estrangeiros. Identificar as cartilhas e os livros de alfabetização na sua rede de relações ou no circuito da comunicação (Darnton, 2010) do qual fazem parte, constitui uma das abordagens de pesquisa realizada no grupo nos últimos anos. Sobre algumas dessas cartilhas, no que tange à produção, à circulação, aos projetos pedagógicos e editoriais, as autoras e aos métodos propugnados, já foram realizados estudos como, por exemplo, Peres; Cézar (2003); Peres; Porto (2004); Peres (2006a; 2006b; 2008a; 2008b); Peres; Dietrich (2010); Peres; Facin (2010); Dietrich (2012); Peres (2014).

A tabela 1 contém os dados que apresentam as quantidades de cartilhas nacionais e suas décadas, disponíveis para pesquisa aos interessados na temática ou nas temáticas possíveis e decorrentes desse importante suporte de ensino/aprendizagem da leitura e da escrita na escola.

Tabela 1 -

Cartilhas e livros de alfabetização em língua nacional pertencentes ao acervo do grupo de pesquisa Hisales.

\begin{tabular}{c|c}
\hline \multicolumn{2}{c}{ Cartilhas e livros de alfabetização em língua nacional } \\
\hline Década & Quantidade \\
\hline 1900 & 01 \\
\hline 1910 & 02 \\
\hline
\end{tabular}

${ }^{4}$ O glossário do Ceale - Termos de alfabetização, leitura e escrita para educadores (2014), apresenta no verbete Cartilhas e materiais para aprender a ler, de autoria de Francisca Izabel Pereira Maciel e Isabel Cristina Alves da Silva Frade, algumas definições sobre cartilhas e livros de alfabetização, que podem ser vistas no link http://ceale.fae.ufmg.br/app/webroot/ glossarioceale/verbetes/cartilhas-e-materiais-paraaprender-a-ler. 


\begin{tabular}{c|c}
\hline 1920 & - \\
\hline 1930 & 01 \\
\hline 1940 & 03 \\
\hline 1950 & 10 \\
\hline 1960 & 18 \\
\hline 1970 & 49 \\
\hline 1980 & 84 \\
\hline 1990 & 238 \\
\hline 2000 & 366 \\
\hline 2010 & 66 \\
\hline sem identificação & 71 \\
\hline Total & 909 \\
\hline
\end{tabular}

Fonte: Grupo de pesquisa Hisales (junho 2015).

É importante salientar que são separados, no acervo e nos estudos, cartilhas produzidas por autoras gaúchas das demais - produção nacional e estrangeira. Isso se deve ao fato de que há um interesse maior na realização de pesquisas específicas dos livros para ensino da leitura e da escrita produzidos no Rio Grande do Sul. Esses materiais ajudam a identificar os complexos e variados aspectos que explicam as mudanças e permanências no ensino da leitura e da escrita em nível local, bem como na identificação da autoria dessas cartilhas e nas trajetórias individuais, profissionais e institucionais dos autores e autoras de livros no estado gaúcho. É importante salientar que se trata de um material difícil de obter, especialmente em razão do período de sua produção - final do século 19 até final dos anos de 1970. Do conjunto das 909 cartilhas e livros para o ensino inicial da leitura e da escrita do acervo, apenas 34 são produções gaúchas - cartilhas de autoras ou publicadas por editoras do Rio Grande do Sul.

A seguir, na tabela 2, são apresentados os dados relativos às cartilhas e aos livros de alfabetização em língua estrangeira, que também são adquiridos pelos integrantes do grupo, recebidos em doações e em trocas realizadas com pesquisadores de outros países também interessados na temática.

Essa troca é feita, especialmente, com o grupo Reading Primers Special Interest Group - RP-SIG -, com sede na Alemanha, que reúne pesquisadores do mundo todo, em especial do Norte da Europa. Trata-se de um grupo ligado a International Society for Historical and Systematic Research on Schoolbooks ${ }^{5}$. Temos mantido um intercâmbio

\footnotetext{
5 "The International Society for Historical and Systematic Research On Schoolbooks e.V. was founded in 1997 under the chairmanship of Prof. Dr. Dr. Werner Wiater (professor for the theory of school education at the University of Augsburg) as a scientific society. Its goal is to further the interdisciplinary, historical and systematic research on textbooks on a large scale and to bring its importance to public attention. By means of regular conferences and publications (see below), the society wants to offers a forum for researchers on textbooks, also for young scientists; it offers the opportunity to apply single investigations more effectively to each other, to link them, and to discuss them in an international context. Theoretical and methodical issues with regard to the research on textbooks are considered, and problems connected with the development and the revision of textbooks are discussed. Furthermore, the society is keen to inspire a dialogue about textbooks between researchers, authors and publishers, teachers, pupils, and the interested public". http://www.philso.uni-augsburg.de/en/lehrstuehle/paedagogik/igschub/society/
} 
interessante com esse grupo, tendo inclusive publicado um artigo em um catálogo organizado pelo RP-SIG ${ }^{6}$. Principalmente graças a esse intercâmbio o acervo de cartilhas estrangeiras está constituído pelo que se demonstra na tabela a seguir.

Tabela 2 -

Cartilhas e livros de alfabetização em língua estrangeira pertencentes ao acervo do grupo de pesquisa Hisales.

\begin{tabular}{l|c}
\hline \multicolumn{2}{c}{ Cartilhas e livros de alfabetização em língua estrangeira } \\
\hline Língua & Quantidade \\
\hline Inglês & 32 \\
\hline Espanhol & 13 \\
\hline Línguas locais das Ilhas Papua Nova & 12 \\
Guiné & 11 \\
\hline Alemão & 10 \\
\hline Francês & 07 \\
\hline Russo & 06 \\
\hline Dinamarquês & 06 \\
\hline Quom- (indígena/Espanha) & 03 \\
\hline Letão & 03 \\
\hline Lituano & 03 \\
\hline Português (PT) & 02 \\
\hline Italiano & 02 \\
\hline Árabe & 01 \\
\hline Basco & 01 \\
\hline Hindi & 01 \\
\hline Chinês & 01 \\
\hline Faroese (Ilhas Faroes, Dinamarca) & 01 \\
\hline Estoniano (Estônia) & 01 \\
\hline Livoniano (Estônia) & 01 \\
\hline Sueco & 01 \\
\hline Irlandês & 01 \\
\hline Holandês & 05 \\
\hline Bilíngue & 02 \\
\hline Não identificadas & 126 \\
\hline Total &
\end{tabular}

Fonte: Grupo de pesquisa Hisales (junho 2015).

Trata-se de um material bastante rico e disponível para pesquisas, especialmente as de cunho comparativo. Nenhum trabalho foi feito ainda tomando este acervo para estudo.

\footnotetext{
${ }^{6}$ PERES, Eliane Teresinha; ARRIADA, Eduardo. Fibel oder der Schereib-Lese-Unterricht. A. Haesters Fibel bearbeitet für die deutshen Shulen in Brasilien. In: GERT, GeiBler; SROKA, Wendelin: WOJDON, Joanna (org.). Lesen Lernen... Mehrspraching. Fibeln und Lesebücher aus Europa und Amerika. 1ed.Bonn/Essen: Alle Rechte bei den Herausgebern, 2011, v. 1, p. 74-75. O RP-SIG mantém também uma publicação trimestral chamada Newsletter que pode ser consultada em: http://abc-world.nl/resources/texts/news/RPI1.pdf.
} 


\section{Livros didáticos elaborados por autoras gaúchas ${ }^{7}$ entre 1940 e 1980}

O acervo de livros didáticos gaúchos possui 267 exemplares, datados entre os anos de 1940 e 1980. Esses livros, até o momento, aparecem em duas categorias: livros que apresentam indícios de pertenceram a uma coleção, ou seja, mais de um livro completando uma série didática e livros avulsos, nos quais existe apenas um livro para determinada série escolar ou segmento do ensino. Tal material possui uma característica peculiar: é constituído, quase em sua totalidade, por obras produzidas por técnicas e orientadoras em educação do Centro de Pesquisas e Orientação Educacionais da Secretaria de Educação e Cultura do Rio Grande do Sul - CPOE -, que se especializaram na produção didática em todas as áreas do conhecimento. Além disso, tratam-se de livros didáticos conhecidos por inúmeras gerações de professoras e alunos das escolas gaúchas.

Os livros foram editados, tanto por empresas do Rio Grande do Sul - Selbach, Tabajara, Globo -, quanto por empresas de fora do Estado - Editora do Brasil, FTD. Como a produção didática centralizou-se, pós 1980, no eixo Rio-São Paulo-Belo Horizonte, com o fenômeno da globalização no campo editorial, muitas das editoras gaúchas que editavam esses livros fecharam suas portas ou transferiram suas sedes e, com isso, a produção de livros didáticos no Estado do Rio Grande do Sul praticamente acabou. Reunir esse legado, os livros aqui produzidos, tem sido um esforço empreendido pelo grupo de pesquisa Hisales. Estudá-lo tem sido um desafio ainda maior. É possível encontrar alguns trabalhos mais específicos sobre coleções de livros didáticos do acervo em dissertações e teses defendidas no PPGE da UFPel: Alves (2005; 2013); Ramil (2013; 2015); Dietrich (2012); Vahl (2014). Muito ainda está para ser feito nesse campo.

A tabela 3 mostra a quantidade de exemplares desse acervo classificados por década.

Tabela 3 -

Livros didáticos produzidos no RS (1940-1980) pertencentes ao acervo do grupo de pesquisa Hisales.

\begin{tabular}{c|c}
\hline \multicolumn{2}{|c}{ Livros didáticos produzidos no RS (1940-1980) } \\
\hline Década & Quantidade \\
\hline 1940 & 01 \\
\hline 1950 & 16 \\
\hline 1960 & 76 \\
\hline 1970 & 101 \\
\hline 1980 & 04 \\
\hline sem identificação & 69 \\
\hline Total & 267 \\
\hline
\end{tabular}

Fonte: Grupo de pesquisa Hisales (junho 2015).

Passamos, a seguir, a descrição de outro acervo: o de cadernos de alunos em fase de alfabetização.

\footnotetext{
${ }^{7}$ Trata-se usar o feminino para ser fiel ao acervo: quase todos os livros são de autoria de mulheres. Esse é um dado que em hipótese alguma pode ser desconsiderado em qualquer análise sobre a produção didática gaúcha. 


\section{Cadernos de alunos em fase de alfabetização}

$\mathrm{O}$ acervo de cadernos de alunos em fase de alfabetização é composto de 393 cadernos de crianças, datados de 1930 a 2013, tabela 4. Por cadernos de alfabetização compreendemos aqueles em que há registro do ensino sistemático da leitura e da escrita: pré-escolar, $1^{\mathrm{a}}$ série, $1^{\circ}$ ano, e em alguns casos, pós $2010,2^{\mathrm{a}}$ série e $2^{\circ}$ ano. Essa escolha se deve ao fato de que as pesquisas no campo da história da alfabetização costumam ser privilegiadas.

Contudo, é preciso destacar que tais materiais podem ser utilizados, tanto para a realização de estudos relacionados ao ensino-aprendizagem da língua escrita, quanto para compreender a cultura escolar de um modo geral. Vinão (2008) ressalta que nas duas últimas décadas os estudos com cadernos escolares vêm se configurando no cruzamento de três campos historiográficos relacionados e complementares, mas com diferentes enfoques e interesses: "a história da infância, da cultura escrita e da educação" (p. 15). No caso brasileiro somam-se a esses campos historiográficos os recentes estudos referentes à história da alfabetização, com destaque para os métodos de ensino e os livros destinados ao processo inicial de aquisição da leitura e da escrita. Entre as produções decorrentes desse acervo destacam-se os estudos que tomaram o ditado como objeto de análise (Peres; Barum, 2008; Barum, 2012); as estratégias de correção das professoras (Peres; Dietrich; Barum, 2011); as concepções e práticas de alfabetização (Peres, 2010; Porto; Peres, 2011; Peres, 2012); os registros espontâneos das crianças (Peres; Nogueira, 2014). No entanto, muito ainda está para ser pesquisado no acervo dos cadernos de alunos.

A seguir apresentamos o número de cadernos do acervo considerando as décadas. Antes, ainda, ressaltamos que organizamos as coleções por décadas para que os pesquisadores possam visualizar as possibilidades de estudos longitudinais e comparativos.

Tabela 4 -

Cadernos de alunos em fase de alfabetização pertencentes ao acervo do grupo de pesquisa Hisales.

\begin{tabular}{c|c}
\hline \multicolumn{2}{c}{ Cadernos de alunos em fase de alfabetização } \\
\hline Década & Quantidade \\
\hline 1930 & 02 \\
\hline 1940 & 03 \\
\hline 1950 & 02 \\
\hline 1960 & 09 \\
\hline 1970 & 10 \\
\hline 1980 & 20 \\
\hline 1990 & 75 \\
\hline 2000 & 153 \\
\hline 2010 & 102 \\
\hline Sem identificação & 17 \\
\hline Total & 393 \\
\hline
\end{tabular}

Fonte: Grupo de pesquisa Hisales (junho 2015). 
Além dos cadernos supracitados, também temos exemplares de outras séries escolares, que estão sendo catalogados e inseridos no acervo. No próximo item sintetizamos os dados de outra coleção disponível para pesquisa: a dos cadernos de planejamento de professoras.

\section{Cadernos de planejamento - diários de classe - de professoras alfabetizadoras}

Os cadernos de planejamentos de professoras alfabetizadoras totalizam 156 exemplares, produzidos entre 1960 e 2010, conforme mostra a tabela 5. É importante esclarecer que se trata dos planejamentos manuscritos nos quais são registradas as atividades cotidianas previstas pela professora, feitos previamente às aulas, ou seja, são os planejamentos diários das rotinas, exercícios e tarefas programas para os alunos.

Em sua maioria são cadernos do tipo grande e que revelam, de alguma forma, um habitus pedagógico da docência das séries iniciais: são coloridos, com adesivos, recortes e desenhos feitos pelas próprias professoras. No Rio Grande do Sul convencionou-se chamar esses cadernos de diários de classe. Entre os trabalhos que apresentam pesquisas sobre tais cadernos estão as dissertações de mestrado de Lima (2013) e Vieira (2014), defendidas no PPGE da UFPel. O acervo tem potencial de pesquisa sobre diferentes aspectos do trabalho docente e da cultura escolar, especialmente da cultura da alfabetização.

Tabela 5 -

Cadernos de planejamento de professoras alfabetizadoras pertencentes ao acervo do grupo de pesquisa Hisales.

\begin{tabular}{c|c}
\hline \multicolumn{2}{c}{ Cadernos de planejamento de professoras alfabetizadoras } \\
\hline Década & Quantidade \\
\hline 1960 & 03 \\
\hline 1970 & 09 \\
\hline 1980 & 41 \\
\hline 1990 & 50 \\
\hline 2000 & 45 \\
\hline 2010 & 08 \\
\hline Total & 156 \\
\hline
\end{tabular}

Fonte: Grupo de pesquisa Hisales (junho 2015).

Por fim, a última coleção que estamos formando e organizando será apresentada a seguir.

\section{Materiais didático-pedagógicos diversos}

O grupo de investigação Hisales também possui materiais didático-pedagógicos de diferentes épocas que podem colaborar no estudo da história do ensino da leitura e da escrita, de um modo especial e da cultura escolar em geral.

São itens, habitualmente, descartados após o uso na escola e que representam concretamente aspectos importantes da cultura material escolar de diferentes períodos. Com esses materiais podem ser realizadas pesquisas que analisam, por exemplo, as diferentes metodologias de ensino e aprendizagem aplicadas nos anos iniciais, 
especialmente na alfabetização. Tais objetos permitem que se identifiquem vestígios do cotidiano e das práticas das salas de aula, embora, obviamente, não seja possível apreender o que aconteceu na totalidade dessas práticas escolares.

No quadro a seguir vê-se a relação de alguns dos materiais disponíveis no Hisales e já catalogados e identificados neste acervo.

\section{Quadro 1 -}

Materiais didático-pedagógicos diversos pertencentes ao acervo do grupo de pesquisa Hisales.

\begin{tabular}{|l|l|l|l|}
\hline \multicolumn{4}{|c|}{ Materiais didático-pedagógicos } \\
\hline Lápis & Esquadro & $\begin{array}{l}\text { Cadernos de } \\
\text { chamada }\end{array}$ & Matriz de mimeógrafo \\
\hline Lapiseira & Gabarito & Agenda & Palmatória \\
\hline Caneta & Compasso & Cartaz & Sineta \\
\hline Marcador & Giz de quadro negro & Pôster & Pasta escolar \\
\hline Giz de cera & $\begin{array}{l}\text { Estojo de giz de } \\
\text { quadro negro }\end{array}$ & Mapa/Atlas & Flâmula \\
\hline Lápis de cor & Apagador & Pasta com trabalhos & Flanelógrafo \\
\hline Caneta hidrocor & Alfabetário & $\begin{array}{l}\text { Kit de materiais } \\
\text { relacionados }\end{array}$ & Quadro negro \\
\hline Caneta nanquim & $\begin{array}{l}\text { Alfabeto } \\
\text { montessoriano }\end{array}$ & Prova & Pedra de ardósia \\
\hline Bico de pena & Ábaco & Exercício & Corretivo líquido \\
\hline Tinta nanquim & Fantoche e dedoche & Desenho & Certificado \\
\hline Tinteiro & Dominó & Colagem & Diploma \\
\hline Borrador & Quebra-cabeça & $\begin{array}{l}\text { Trabalho } \\
\text { tridimensional }\end{array}$ & Classe avulsa \\
\hline Borracha & Jogo variado & Folha mimeografada & Cadeira avulsa \\
\hline Apontador & Carimbo & Folha xerocada & $\begin{array}{l}\text { Classe p/ 1 aluno com } \\
\text { assento acoplado }\end{array}$ \\
\hline Estojo de aluno & Boletim & Folha impressa & $\begin{array}{l}\text { Classe p/ 2 alunos com } \\
\text { assento acoplado }\end{array}$ \\
\hline Régua & Caderneta & $\begin{array}{l}\text { Classes p/ 3 alunos com } \\
\text { assento acoplado }\end{array}$ \\
\hline
\end{tabular}

Fonte: Grupo de pesquisa Hisales.

Este é o acervo cuja catalogação dos itens é a mais recente entre todos os outros. Embora as doações, a coleta e a aquisição de materiais didático-pedagógicos venham acontecendo há algum tempo, as atividades de identificação, classificação e cadastro foram iniciadas em 2014, favorecidas pela concessão de bolsistas de extensão.

Esse acervo também tem, entre suas funções, a de contribuir com as exposições do projeto de extensão Memórias da alfabetização, que são realizadas em eventos específicos de educação e em locais de ampla circulação de pessoas.

Até o momento há o registro de 250 fichas cadastrais desse acervo, que são utilizadas na catalogação e que identificam, tanto os materiais individuais e avulsos, quanto os materiais armazenados coletivamente - conjunto de lápis, por exemplo. 


\section{A organização dos acervos do Hisales}

O trabalho de constituição e organização dos acervos é realizado por integrantes do grupo que, por visar a preservação e conservação, desenvolvem as seguintes etapas: a) coleta de materiais: doações individuais e institucionais ou compra; b) triagem; c) limpeza e higienização; d) classificação, catalogação e organização; e) armazenamento. Todas as aquisições e doações passam por processos e tratamentos específicos, para então fazerem parte dos acervos a que serão destinados. A seguir, apresentamos algumas das ações desenvolvidas e dos processos metodológicos adotados com os itens dos acervos.

\section{Processo de higienização, conservação e armazenamento}

Os processos de higienização, conservação e armazenamento adotados com os materiais recebidos não são ainda os ideais, devido à falta de subsídios financeiros, de estrutura e de espaço adequado. Apesar disso, considerando as limitações e as possibilidades do trabalho, os integrantes têm realizado as três etapas do processo: higienização, conservação e armazenamento. Sempre que possível frequentam oficinais e mini cursos de conservação e organização de acervos.

O grupo tem uma característica interdisciplinar e os integrantes que participam do trabalho de organização e manutenção dos acervos são oriundos de distintas áreas de formação. Para complementar os conhecimentos para o desenvolvimento do trabalho buscamos técnicas e referências acessíveis para a organização e o tratamento dos materiais, com vistas a promover articulações com pessoas de áreas técnicas que podem contribuir com formação específica para tal.

\section{Processos de catalogação}

Os acervos do Hisales são catalogados separadamente e, devido a suas especificidades, cada um possui um sistema de cadastro das informações de acordo com os dados que são relevantes para sua identificação e para as pesquisas que envolvem as temáticas específicas.

Como ainda não foi possível desenvolver um programa de banco de dados específico do Hisales, pela dificuldade em obter financiamento específico para tal fim, as informações de identificação dos exemplares são preenchidas em softwares de edição de textos e de planilhas, com utilização de campos distribuídos em tabelas ou pelo formato de ficha cadastral com campos definidos coletivamente no grupo.

$\mathrm{Na}$ planilha de registro dos dados de catalogação das cartilhas e dos livros de alfabetização são considerados os seguintes campos: título, autores, ilustradores, editora, cidade, edição, ano, número de exemplares, década.

Os dados dos livros didáticos produzidos no Rio Grande do Sul estão descritos em tabelas com a relação das coleções e as informações específicas estão dispostas em fichas cadastrais individuais que destacam o registro dos campos tais como: autores, título, coleção, ilustradores, editora, local, edição, ano publicação, páginas, exemplares, localização. Essas fichas também estão fixadas no exterior das caixas de proteção individual dos livros, confeccionadas com cartona pelos integrantes do grupo, para facilitar a identificação do conteúdo e manter o objeto protegido da ação do tempo. 
Já nos cadernos de crianças em fase de alfabetização a planilha de catalogação possui os seguintes campos: década, ano, identificação, série/ano, gênero do aluno, escola, cidade, período de registro das aulas, observação, entre outros. Os cadernos são armazenados individualmente em caixas igualmente confeccionadas com cartonas e são identificadas, na parte externa, com uma ficha contendo os principais dados da planilha.

Os dados dos cadernos de planejamento de professoras alfabetizadoras estão descritos tanto em planilhas, quanto em fichas individuais que destacam os principais dados desses materiais, distribuídos em campos como: década, identificação, série/ano, escola, cidade, período de registro das aulas, observação. Esses cadernos também são armazenados em caixas individuais de cartona confeccionadas para esse fim, que contém, externamente, a identificação do conteúdo, feita por fichas.

Quanto à catalogação dos materiais didático-pedagógicos, os dados são organizados em uma ficha cadastral específica, criada pela doutoranda e integrante do grupo de pesquisa Hisales Chris de Azevedo Ramil, que tem como objetivo orientar a catalogação de acordo com o tipo de material, suas características físicas e sua origem. A ficha cadastral é constituída de cinco campos de identificação: Campo 1: apresenta a cota aplicada como código de identificação do material catalogado, que contém quatro partes. Campo 2: apresenta os possíveis materiais classificados em 18 categorias, nomeadas de A a R e separadas por sub-campos. Campo 3: apresenta dados das principais características físicas e materiais do objeto. Campo 4: apresenta dados referentes à origem, doação e utilização; Campo 5: apresenta as fotos de diferentes ângulos e posições do material catalogado, para identificação visual. Esses materiais estão armazenados de formas diferentes - em caixas, envelopes, sacos -, devido aos seus variados formatos e com o intuito de garantir a melhor forma de acondicionamento. Todos os itens recebem uma etiqueta com uma cota de identificação, que é fixada por um barbante na embalagem dos objetos.

Cabe salientar que os métodos adotados para os registros dos dados dos acervos não adotam normas de catalogação da museologia e buscam agregar informações que deem conta das especificidades previstas para identificação desses materiais, com a finalidade de subsidiar pesquisas e na promoção das exposições anteriormente referidas.

É importante registrar que todos os acervos estão sendo registrados com imagens, dentro das possibilidades técnicas. No caso das cartilhas e livros de alfabetização nacionais e estrangeiras, livros didáticos produzidos no Rio Grande do Sul, cadernos de alunos em fase de alfabetização e cadernos de planejamento de professoras alfabetizadoras, as capas são digitalizadas. Já no caso dos materiais didáticopedagógicos, os itens existentes estão sendo fotografados.

Com as catalogações explicitadas acima, qualquer pesquisador interessado nos materiais pode, primeiro, ter contato com alguma forma de registro escrito que possibilita ter uma ideia da natureza, da quantidade, da periodização, das informações mais relevantes contidas em cada acervo, para só então consultar o acervo físico.

Com a implementação de uma parceria com o Sistema de Bibliotecas da UFPel, desde o início de 2014, está sendo feita a inserção dos acervos em versão virtual no sistema Pergamum, banco de dados virtual para gerenciamento de acervos, utilizado pela 
instituição para registro, cadastro, organização e pesquisa de livros via internet. Este sistema possibilita que o usuário consulte o catálogo online e a pesquisa pode ser feita pela web.

\section{Considerações finais}

O grupo de pesquisa Hisales pretende, com a constituição e a manutenção de seus acervos, contribuir para o fortalecimento das discussões e das pesquisas em História da Educação, da alfabetização, da leitura, da escrita e dos livros escolares, tanto em estudos que possam ser desenvolvidos na graduação, quanto na pós-graduação.

Estes acervos, constituídos de materiais que não são de fácil aquisição, contribuem na manutenção da História da Educação do Rio Grande do Sul e com a valorização da história profissional de professoras e autoras gaúchas, assim como na preservação e guarda do patrimônio escolar. O foco central do trabalho de constituição das coleções tem sido os materiais escolares que podem revelar a história da alfabetização em geral e gaúcha em especial.

Cabe destacar que além das dissertações e teses citadas neste trabalho, vários artigos têm sido produzidos tomando os materiais do acervo como objetos de estudo. Contudo, um aspecto que merece destaque é o esforço que temos feito nas discussões metodológicas acerca de pesquisas que tomam livros e cadernos escolares como fontes ou objetos de investigação. Uma das principais discussões é sobre o estatuto de fontes de pesquisa que damos aos objetos escolares ordinários, o que podem revelar e como devemos e podemos inquiri-los. Esse tem sido um ganho importante e que as teses, as dissertações e os artigos que produzimos revelam.

Atualmente, os acervos do grupo de pesquisa Hisales estão entre os de maior relevância na área de alfabetização em nível nacional. Apesar das limitações do trabalho, a manutenção, a catalogação, a conservação e a preservação dos materiais são realizadas com grande empenho. Espera-se que os acervos incentivem 0 desenvolvimento de novas pesquisas e ajudem na inovação de procedimentos metodológicos no campo da pesquisa histórica.

Nosso objetivo é deixar para as novas gerações de pesquisadores um legado que permita que a pesquisa educacional avance e revele histórias e memórias plurais do passado. Assim, o Hisales pretende continuar investindo na coleta de fontes documentais e na campanha de arrecadação e guarda de materiais que possam integrar os acervos e abrir novas possibilidades de pesquisa.

\section{Referências}

ALVES, Antônio Maurício Medeiros. A matemática moderna no ensino primário (19601978): análise das coleções de livros didáticos Estrada lluminada e Nossa Terra Nossa Gente. Pelotas: UFPel, 2013. 320f. Tese (doutorado em Educação). Faculdade de Educação, Universidade Federal de Pelotas.

ALVES, Antônio Maurício Medeiros. Livro didático de matemática: uma abordagem histórica. Pelotas: UFPel, 2005. 178f. Dissertação (mestrado em Educação). Faculdade de Educação, Universidade Federal de Pelotas. 
BARUM, Sylvia. Uma atividade de fixação e avaliação: orientações sobre o ditado escolar em cartilhas e livros de alfabetização (1900-1990). SEMINÁRIO DE PESQUISA EM EDUCAÇÃO DA REGIÃO SUL, 9, 2012. Anais ... Caxias do Sul: Anped, 2012.

CAMARGO, Célia Reis. Os centros de documentação das universidades: tendências e perspectivas. In: SILVA, Zélia Lopes (org.). Arquivos, patrimônio e memória: trajetórias e perspectivas. São Paulo: Unesp/Fapesp, 1999, p. 49-63.

DARNTON, Robert. O beijo de Lamourette: mídia, cultura e revolução. São Paulo: Companhia das Letras, 2010.

DIETRICH, Mara Denise. A cartilha Ler a Jato e o método audiofonográfico de alfabetização da professora Gilda de Freitas Tomatis (1967-1986). 180f. Pelotas: UFPel, 2012. Dissertação (mestrado em Educação). Faculdade de Educação, Universidade Federal de Pelotas.

KIRCHNER, Cássia Aparecida Magalhães. O caderno de alunos e professoras como produtor da cultura escolar. CONGRESSO DE ENSINO E PESQUISA DE HISTÓRIA EDUCAÇÃO, 5, 2008. Anais ... Belo Horizonte: UFMG, 2008.

LIMA, Gisele Ramos de. Uma análise dos exercícios com sílabas em diários de classe de professoras alfabetizadoras (1973-2010). Pelotas: UFPel, 2013. 111f. Dissertação (mestrado em Educação). Faculdade de Educação, Universidade Federal de Pelotas.

PERES, Eliane. Aprendendo formas de pensar, se sentir e de agir: discursos pedagógicos e práticas escolares na escola pública. Belo Horizonte: UFMG, 2000. 506f. Tese (doutorado em Educação). Universidade Federal de Minas Gerais.

PERES, Eliane. A produção e a circulação de cartilhas escolares no Rio Grande do Sul: alguns dados de pesquisa. In: FRADE, Isabel Cristina Alves da S.; MACIEL, Francisca Isabel P (orgs.). História da alfabetização: produção, difusão e circulação de livros (MG/ RS/MT, séc. XIX e XX). Belo Horizonte: Ceale/Fapemig, CNPq, UFMG/FaE, 2006a, p. 145-170.

PERES, Eliane. Aspectos da produção didática da professora Cecy Cordeiro Thofhern. In: FRADE, Isabel Cristina Alves da S.; MACIEL, Francisca Isabel (orgs.). História da alfabetização: produção, difusão e circulação de livros (MG/RS/MT, séc. XIX e XX). Belo Horizonte: Ceale/Fapemig, CNPq, UFMG/FAE, 2006b, p. 171-190.

PERES, Eliane. Produção de cartilhas escolares no Rio Grande do Sul entre as décadas de 1950 e 1970: contribuições à história da alfabetização e das práticas escolares. ENDIPE, 14, 2008. Anais ... Porto Alegre: PUCRS, 2008a, v. 1, p. 1-12.

PERES, Eliane. Autoras de obras didáticas e livros para o ensino da leitura produzidos no Rio Grande do Sul: contribuições à história da alfabetização (1950-1970). Educação Unisinos, v. 12, 2008b, p. 111-121.

PERES, Eliane. Um estudo da história da alfabetização através de cadernos escolares (1943-2010). Cadernos de História da Educação (UFU. Impresso), v. 11, 2012, p. 93-106.

PERES, Eliane. Influências do pensamento norte-americano na produção de cartilhas para o ensino da leitura e da escrita no Rio Grande do Sul na década de 1960. In: MORTATTI, Maria do Rosário Longo; FRADE, Isabel Cristina Aves da Silva (org.). História do ensino de leitura e escrita, métodos e material didático. Marília: Unesp, 2014, p. 93-120. 
PERES, Eliane; BARUM, Sylvia. O ditado escolar sob o enfoque histórico: um estudo a partir de cadernos de crianças em processo de alfabetização (1943-2007). ENCONTRO DA ASSOCIAÇÃO SUL-RIO-GRANDENSE DE PESQUISADORES EM HISTÓRIA DA EDUCAÇÃO, 14, 2008. Anais ... Pelotas: UFPel, 2008.

PERES, Eliane; CÉZAR, Thais M. Divulgação e a adoção do método global de ensino da leitura no Rio Grande do Sul (1940-1970). ENCONTRO DA ASSOCIAÇÃO SUL-RIOGRANDENSE DE PESQUISADORES EM HISTÓRIA DA EDUCAÇÃO, 9, 2003. Anais ... Pelotas: Asphe, 2003.

PERES, Eliane; DIETRICH, Mara Denise. A cartilha Ler a Jato e o método audiofonográfico: uma proposta de alfabetização de uma professora gaúcha para o fim do analfabetismo no país (décadas de 1960-70). In: BARCELOS, Valdo Hermes de Lima; ANTUNES, Helenise Sangoi (orgs.). Alfabetização, letramento e leitura: territórios formativos. Santa Cruz do Sul: Unisc, 2010, p. 50-68.

PERES, Eliane; DIETRICH, Mara Denise; BARUM, Sylvia. Lindo! Expressões e frases de incentivo às crianças feitas por professoras-alfabetizadoras em cadernos escolares (anos de 1940-2000). CONGRESSO BRASILEIRO DE HISTÓRIA DA EDUCAÇÃO, 6, 2011. Anais ... Vitória: SBHE, 2011.

PERES, Eliane; FACIN, Helenara P. A produção didática da professora Nelly Cunha e suas contribuições para o ensino da leitura no Rio Grande do Sul (décadas de 19601980). In: SCHWARTZ, Cleonara; PERES, Eliane; FRADE, Isabel Cristina A. S (orgs.). Estudos de história da alfabetização e da leitura na escola. Vitória: Ufes, 2010, p. 137170.

PERES, Eliane; NOGUEIRA, Gabriela Medeiros. Registros marginais: escritas de crianças em cadernos escolares de pré-escola e $1^{\circ}$ ano (1930-2010). SIMPÓSIO LUSOBRASILEIRO EM ESTUDOS DA CRIANÇA, 2, 2014. Anais ... Porto Alegre: Ufrgs, 2014.

PERES, Eliane; PORTO, Gilceane Caetano. A produção e a circulação de cartilhas do método global de contos de ensino da leitura no Rio Grande do Sul (décadas de 40-70). In: LEAHY-DIOS, Cyana (org.). Espaços e tempos de educação. Rio de Janeiro: Brasa, 2004, p. 26-40.

PORTO, Gilceane Caetano; PERES, Eliane Teresinha. Concepções e práticas de alfabetização vista através de cadernos escolares. Cadernos de Educação (UFPel), v. 40, 2011, p. 56-78.

QUADROS, Claudemir de. Reforma, ciência e profissionalização da educação: o Centro de Pesquisas e Orientação Educacionais do Rio Grande do Sul. Porto Alegre: Ufrgs, 2006. 428f. Tese (doutorado em Educação). Faculdade de Educação, Universidade Federal do Rio Grande do Sul.

RAMIL, Chris de Azevedo. A coleção didática Tapete Verde: do projeto à sua produção gráfica (década de 1970 - Rio Grande do Sul). Pelotas: UFPel, 2013. 223f. Dissertação (mestrado em Educação). Faculdade de Educação, Universidade Federal de Pelotas.

RAMIL, Chris de Azevedo. Edições Tabajara: notas iniciais sobre as publicações didáticas e seus aspectos editoriais. ENCONTRO DE PÓS-GRADUAÇÃO UFPEL, 16, 2014. Anais ... Pelotas: UFPel, 2014. 
RAMIL, Chris de Azevedo. A iconografia e a iconologia didática: um estudo das imagens nos livros didáticos gaúchos das Edições Tabajara (1950-1970). 106f. Pelotas: UFPel, 2015. Projeto de tese (doutorado em Educação). Faculdade de Educação, Universidade Federal de Pelotas.

VAHL, Mônica Maciel. O programa do livro didático para o ensino fundamental do Instituto Nacional do Livro - PLIDEF/INL (1971-1976): um estudo sobre as condições históricas e sociais e as paradas em jogo no campo. 293f. Pelotas: UFPel, 2014. Dissertação (mestrado em Educação). Faculdade de Educação, Universidade Federal de Pelotas.

VIEIRA, Cícera Marcelina. O uso de cartilhas no processo de alfabetização: um estudo a partir de cadernos de planejamento de uma professora (1983-2000). 212f. Pelotas: UFPel, 2014. Dissertação (mestrado em Educação). Faculdade de Educação, Universidade Federal de Pelotas.

VINÃO, Antonio. Os cadernos escolares como fonte histórica: aspectos metodológicos e historiográficos. In: MIGNOT, Ana Chrystina Venâncio (org.). Cadernos à vista: escola, memória e cultura escrita. Rio de Janeiro: Uerj, 2008, p. 15-33.

ELIANE PERES é professora na Faculdade de Educação da Universidade Federal de Pelotas desde 1991. É licenciada em Pedagogia pela Universidade Estadual de Londrina, com mestrado e doutorado em Educação. Realizou estágio de pósdoutorado na Universidade de Illinois em Urbana - Champaign, nos Estados Unidos. É coordenadora do Grupo de Pesquisa História da Alfabetização, Leitura, Escrita e dos Livros Escolares - Hisales.

Endereço: Rua Almirante Tamandaré, 227 - 96010-750 - Pelotas - RS - Brasil.

E-mail: eteperes@gmail.com.

CHRIS DE AZEVEDO RAMIL é estudante do curso de doutorado em Educação e mestre em Educação pelo Programa de Pós-Graduação em Educação da Universidade Federal de Pelotas, ambos com bolsa da Capes.

Endereço: Rua Francisco Moreira, 250 - 96077-080 - Pelotas - RS - Brasil.

E-mail: chrisramil@gmail.com.

Recebido em 4 de julho de 2015.

Aceito em 11 de agosto de 2015. 